\title{
Successful living donor liver transplantation in a cystic fibrosis patient with combined hepatocellular carcinoma and cholangiocarcinoma
}

\author{
Falk Rauchfuß, Felix Dondorf, René Fahrner, Michael Ardelt, Yves Dittmar, Utz Settmacher
}

Department of General, Visceral and Vascular Surgery, Jena University Hospital, Friedrich-Schiller-University Jena, 07747 Jena, Germany

\begin{abstract}
Combined hepatocellular carcinoma (HCC) and cholangiocarcinoma (CC) is a rare tumor entity. In this report, we describe a case of a young patient who developed a liver tumor in a cirrhotic liver caused by cystic fibrosis. All diagnostic findings suggested that this tumor was an HCC. We performed living donor liver transplantation. Histological examination of the tumor revealed combined HCC and CC as an incidental finding. Two years after the transplantation, the patient is in good clinical condition and is disease-free.
\end{abstract}

Key words: Cholangiocarcinoma; cystic fibrosis; hepatocellular carcinoma; liver transplantation; liver tumor; living donation

Address for correspondence:

Dr. Falk Rauchfuß, Department of General, Visceral and Vascular Surgery, Jena University Hospital, Friedrich-Schiller-University Jena, Erlanger Allee 101, 07747 Jena, Germany. E-mail: Falk.Rauchfuss@med.uni-jena.de

Received: 29-01-2015, Accepted: 16-02-2015

\section{INTRODUCTION}

Liver cirrhosis is one of the major risk factors for the development of hepatocellular carcinoma (HCC), which is the one of the leading causes of cancer-related deaths worldwide. ${ }^{[1]}$ Cystic fibrosis (CF) might be associated with liver diseases including liver cirrhosis requiring liver transplantation or combined lung-liver transplantation. These hepatobiliary diseases are the third-leading cause of death in CF patients. ${ }^{[2]}$ Combined HCC and cholangiocarcinoma (CC) is a rare tumor entity, which is defined as a tumor in which both HCC and CC components co-exist in either the same tumor or the same liver. ${ }^{[3]}$

As yet, there is no report of a combined HCC and CC in cirrhotic liver caused by CF. We present a case of a young

\begin{tabular}{|l|c|}
\hline \multicolumn{2}{|c|}{ Access this article online } \\
\hline \multirow{2}{*}{ Website: } & Quick Response Code \\
\hline http://www.hrjournal.net/ & \\
DOI: & \\
10.4103/2394-5079.153288 & \\
&
\end{tabular}

patient who was transplanted at our center with an incidental finding of a combined HCC and CC in a cirrhotic liver due to CF.

\section{CASE REPORT}

A 29-year-old patient was admitted to our transplantation unit due to a recently diagnosed liver tumor with underlying liver cirrhosis. The cirrhosis was known and treated for years since the patient suffered from CF since his childhood. The single liver tumor was localized in segment $\mathrm{V}$ with a diameter of $6.5 \mathrm{~cm}$. The computed tomography scan showed a hyper-vascularized tumor in the arterial phase with the aforementioned extent [Figure 1]. Tumor marker analysis showed a marked elevation of $\alpha$-fetoprotein $(808.7 \mathrm{ng} / \mathrm{mL}$, normal range: $<6.6 \mathrm{ng} / \mathrm{mL}$ ) and a slight increase of carbohydrate antigen (CA) 19-9 (48.9 U/mL, normal range: < $37 \mathrm{U} / \mathrm{mL})$. All other tumor markers were normal. Taken together, we diagnosed an HCC in a cirrhotic liver caused by CF. To rule out any extra-hepatic tumor manifestation, a positron emission tomography scan (18-fludeoxyglucose, activity: $222 \mathrm{MBq}$ ) was performed showing a moderately increased glucose metabolism within the liver tumor (standard uptake volume in tumor: 6.5; standard uptake volume in liver: 2.4), but no signs of any extra-hepatic tumor spread [Figure 2]. 


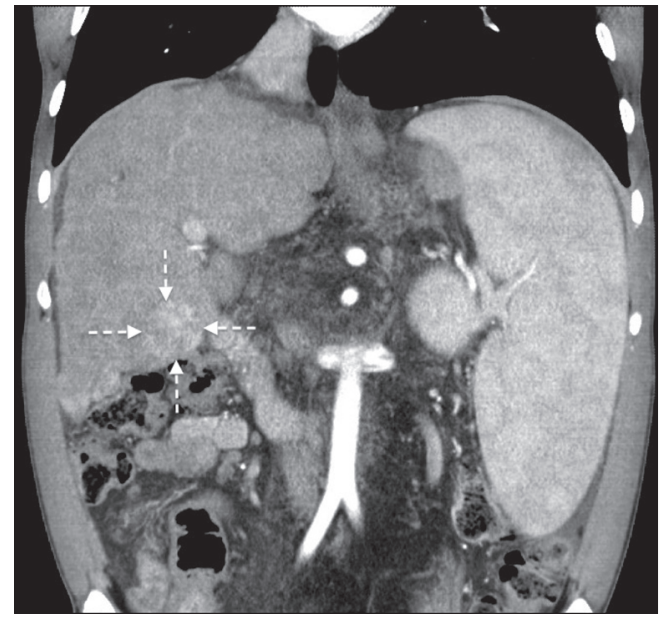

Figure 1: Computed tomography scan of the tumor (white arrows) in the arterial phase

This young patient with a relatively large suspected HCC seemed to be a good candidate for liver transplantation. Despite the CF, the lung function of the patient was good (forced expiratory volume in one second 69\%, forced vital capacity 88\%), and, therefore, a combined lung-liver transplantation was not necessary.

Because the tumor exceeded the Milan criteria, listing the patient for liver transplantation with a Model for End-stage Liver Disease (MELD) exception was not possible. As a "bridging-to-transplant" therapy, we performed a transarterial chemoembolization [Figure 3]. The patient's liver function was still good, reflecting a MELD score of 8 (bilirubin $16 \mu \mathrm{mol} / \mathrm{L}$; creatinine $76 \mu \mathrm{mol} / \mathrm{L}$; international normalized ratio 1.2); therefore the chance of receiving an organ offer within a short time period via a MELD-based allocation was low.

We decided to perform living donor liver transplantation (LDLT). The brother of the patient offered to be the donor. To rule out $\mathrm{CF}$ in the donor, we supplemented our standard donor evaluation procedure with consultation by CF experts. Three months after diagnosis of the tumor, we performed successful LDLT using the right liver lobe as graft.

Surprisingly, the tumor not only showed signs of a HCC (positive for cytokeratin 8, TTF-1 and hepatocyte paraffin 1), but also signs of a CC (positive for cytokeratin 7 and CA 19-9) in the histopathologic examination. Therefore, a combined HCC and CC (Allen and Lisa type C) was diagnosed.

Two years after LDLT, the patient remains disease-free and is in good clinical health. Tumor markers are all in the normal range ( $\alpha$-fetoprotein: $3.9 \mathrm{ng} / \mathrm{mL}$; CA 19-9: $20.1 \mathrm{U} / \mathrm{mL}$ ).

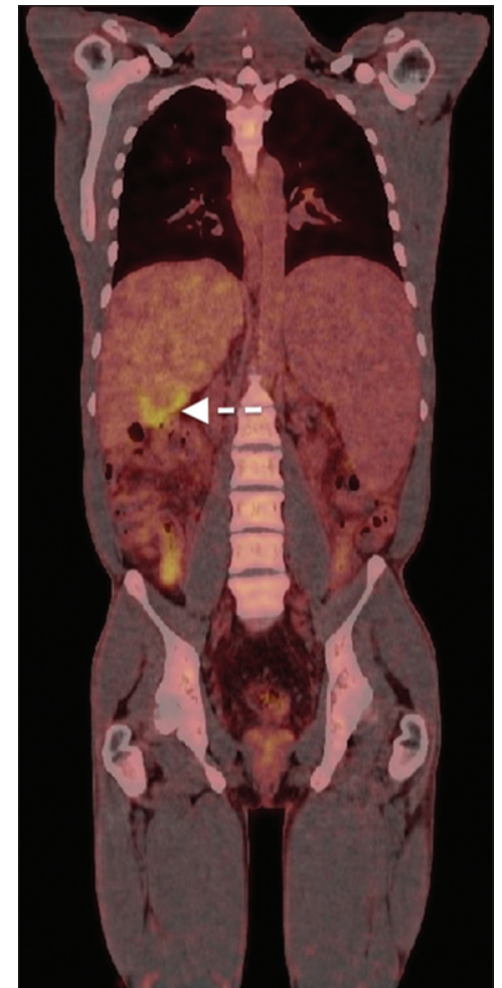

Figure 2: Positron emission tomography scan of the tumor (white arrows) indicating a moderately increased glucose metabolism

\section{DISCUSSION}

To our knowledge, this is the first case of a combined HCC and $\mathrm{CC}$ in a patient suffering from $\mathrm{CF}$ as the underlying disease.

Liver resection provides similar mid-term survival between patients with HCC and patients with combined HCC and CC. However, liver transplantation provides significantly greater 3 years survival for patients with HCC (78\%) compared with patients with combined HCC and CC (48\%). ${ }^{[4]}$ Park et al. ${ }^{[5]}$ described a 5-year survival rate of $60 \%$ after liver transplantation for combined HCC and CC. Most of the patients in this cohort experienced tumor recurrence within the 1 st year after transplantation. In a small patient cohort, two of three patients died due to a metastatic tumor recurrence in the 1 st year after transplantation. ${ }^{[6]}$ Thus, liver transplantation is discussed controversially for patients with combined HCC and CC. In our case, the final diagnosis of the combined HCC and CC was an incidental finding. We did not perform a biopsy of the tumor since the $\alpha$-fetoprotein elevation, and the typical signs in the CT scan suggested an HCC diagnosis. It is a theoretical question whether we would have performed liver resection instead of transplantation if we had known the definitive diagnosis of combined HCC and CC prior to the transplantation. As mentioned before, most publications showed better survival outcome in such patients following liver resection..$^{7,8]}$ 


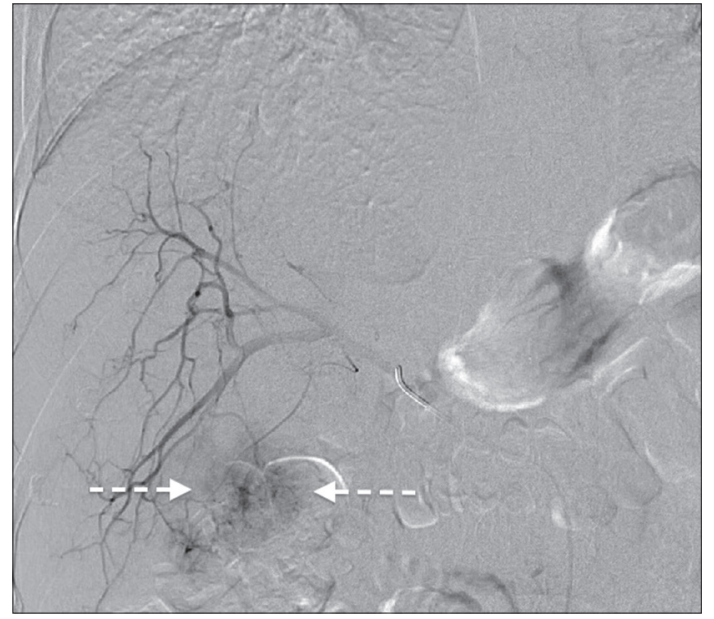

Figure 3: Tumor (white arrows) during the transarterial chemoembolization

The occurrence of a malignant liver disease in patients with $\mathrm{CF}$ is rare. There are a few case reports of HCC in young CF patients. ${ }^{[9-11]}$ Beyond this, there is only one case report describing a CC in a CF patient, who died soon after the diagnosis. ${ }^{[12]}$

In this report, we present the first case describing a combined HCC and CC in cirrhotic liver caused by CF. After successful LDLT, the patient remains disease-free.

\section{REFERENCES}

1. Bruix J, Gores GJ, Mazzaferro V. Hepatocellular carcinoma: clinical frontiers and perspectives. Gut 2014;63:844-55.

2. Herrmann U, Dockter G, Lammert F. Cystic fibrosis-associated liver disease. Best Pract Res Clin Gastroenterol 2010;24:585-92.

3. Yin X, Zhang BH, Qiu SJ, Ren ZG, Zhou J, Chen XH, Zhou Y, Fan J. Combined hepatocellular carcinoma and cholangiocarcinoma: clinical features, treatment modalities, and prognosis. Ann Surg Oncol
2012;19:2869-76

4. Groeschl RT, Turaga KK, Gamblin TC. Transplantation versus resection for patients with combined hepatocellular carcinoma-cholangiocarcinoma. J Surg Oncol 2013;107:608-12.

5. Park YH, Hwang S, Ahn CS, Kim KH, Moon DB, Ha TY, Song GW, Jung DH, Park GC, Namgoong JM, Park CS, Park HW, Kang SH, Jung BH, Lee SG. Long-term outcome of liver transplantation for combined hepatocellular carcinoma and cholangiocarcinoma. Transplant Proc 2013;45:3038-40.

6. Maganty K, Levi D, Moon J, Bejarano PA, Arosemena L, Tzakis A, Martin P. Combined hepatocellular carcinoma and intrahepatic cholangiocarcinoma: outcome after liver transplantation. Dig Dis Sci 2010;55:3597-601.

7. Garancini M, Goffredo P, Pagni F, Romano F, Roman S, Sosa JA, Giardini V. Combined hepatocellular-cholangiocarcinoma: a population-level analysis of an uncommon primary liver tumor. Liver Transpl 2014;20:952-9.

8. Song S, Moon HH, Lee S, Kim TS, Shin M, Kim JM, Park JB, Kwon CH, Kim SJ, Lee SK, Joh JW. Comparison between resection and transplantation in combined hepatocellular and cholangiocarcinoma. Transplant Proc 2013;45:3041-6.

9. McKeon D, Day A, Parmar J, Alexander G, Bilton D. Hepatocellular carcinoma in association with cirrhosis in a patient with cystic fibrosis. J Cyst Fibros 2004;3:193-5.

10. Kelleher T, Staunton M, O’Mahony S, McCormick PA. Advanced hepatocellular carcinoma associated with cystic fibrosis. Eur $J$ Gastroenterol Hepatol 2005; 17:1123-4.

11. O'Donnell DH, Ryan R, Hayes B, Fennelly D, Gibney RG. Hepatocellular carcinoma complicating cystic fibrosis related liver disease. J Cyst Fibros 2009;8:288-90.

12. Tesluk H, McCauley K, Kurland G, Ruebner BH. Cholangiocarcinoma in an adult with cystic fibrosis. J Clin Gastroenterol 1991;13:485-7.

How to cite this article: Rauchfuß F, Dondorf F, Fahrner R, Ardelt M Dittmar $Y$, Settmacher U. Successful living donor liver transplantation in a cystic fibrosis patient with combined hepatocellular carcinoma and cholangiocarcinoma. Hepatoma Res 2015;1:46-8.

Source of Support: Nil. Conflict of Interest: None declared. 